\title{
UJI PERBANDINGAN DAYA ANTIFUNGI EKSTRAK CAIR KULIT BUAH MANGGIS (Garcinia mangostana L) DENGAN DAUN SIRIH (Piper betle L) TERHADAP Candida albicans SEBAGAI BAHAN UTAMA PEMBUATAN VAGINAL DOUCHES
}

\author{
*)Megawati \\ *)Akademi Farmasi Sandi Karsa Makassar \\ *)Program Studi D-III Farmasi Sandi Karsa Makassar
}

\begin{abstract}
ABSTRAK
Telah dilakukan penelitian mengenai Puji dan syukur kepada Allah S.W.T karena limpahan rahmat dan karunianyalah sehingga penelitian dengan Perbandingan Uji Daya Antifungi Ekstrak Cair Kulit Buah Manggis (Garcinia mangostana L) Dengan Daun Sirih (Piper betle L) Terhadap Candida Sp. sebagai Bahan Utama Pembuatan Vaginal Douches. Tujuan penelitian ini mengetahui perbandingan uji daya antifungi ekstrak cair kulit buah manggis (Garcinia mangostana L) dengan daun sirih (Piper betle L) terhadap candida albicans secara In Vitro sebagai bahan utama pembuatan vaginal douches. Untuk mengetahui perbandingan daya antifungi dari kedua sampel tersebut dilakukan penelitian ekspreimental di Laboratorium Mikrobiologi Akademi Farmasi Sandi Karsa. Hasil penelitian menunjukkan bahwa Perlakuan 1 yaitu kontrol negatif tidak menunjukkan adanya kemampuan daya hambat terhadap jamur Candida albicans, untuk perlakuan 2 yaitu kontrol positif, perlakuan 3 , dan 4 memiliki daya hambat kuat dengan diameter $>8 \mathrm{~mm}$. Uji SPSS 20 menunjukkan bahwa ekstrak cair daun sirih memiliki nilai signifikan $0,000(<0,05)$ artinya adanya perbedaan yang signifikan dengan ekstrak cair kulit buah manggis dalam memberikan daya hambat terhadap Candida albicans. Sedangkan Uji BNT menunjukkan perbedaan efek yang nyata terhadap ekstrak cair kulit buah manggis (Garcinia mangostana Linn) dan daun sirih (Piper battle L) terhadap pertumbuhan jamur Candida albicans. Pada ekstrak cair daun sirih (Piper battle L) terhadap kontrol positif tidak terdapat perbedaan yang signifikan karena nilai uji BNT lebih besar dari nilai porbabilitasnya $(0,704>0,05)$.
\end{abstract}

Kata kunci: Antifungi, Garcinia mangostana L, Piper betle L, Candida Sp, Vaginal Douches.

\section{PENDAHULUAN}

\section{A. Latar Belakang}

Infeksi kulit yang disebabkan oleh jamur cukup banyak ditemukan di Indonesia. Salah satu penyebabnya adalah karena indonesai Indonesia merupakan negara tropis yang menyebabkan suhu menjadi beriklim panas dan lembab. Penyebab lain yang bersumber dari manusia itu sendiri seperti kurangnya kesadaran akan kebersihan pada organ tubuh khususnya kulit (Mutiawati, 2016).

Prevalensi penyakit infeksi akibat jamur yang semakin tinggi mendorong pesatnya perkembangan berbagai obat anti jamur. Obatobat antijamur tertentu dapat digunakan untuk mengobati infeksi jamur,akan tetapi sebagian besar antijamur tersebut memiliki satu atau lebih keterbatasan. Oleh karena itu, obat-obatan tradisional merupakan salah satu alternatif pengobatan, disamping obat-obatan modern yang berkembang di pasar (Yanuardani, 2012).

Keputihan sangat berisiko terjadi pada remaja sehingga perlu mendapat perhatian khusus. Masa ini, remaja puteri mengalami pubertas yang ditandai dengan menstruasi. Pada sebagian orang saat mengalami menstruasi dapat mengalami keputihan (Werdiyani, dkk, 2012).
Sikap dan pengetahuan yang kurang dalam melakukan perawatan kebersihan genitalia eksterna (kemaluan bagian luar), serta perilaku yang kurang baik menjadi pencetus keputihan (Azizah, 2015).

Keputihan atau yang disebut juga dengan istilah white discharge atau vaginal discharge, atau leukore atau flour albus. Keputihan yang terjadi pada wanita dapat bersifat normal dan abnormal. Keputihan normal terjadi sesuai dengan proses menstruasi. Gejala keputihan yang normal adalah tidak berbau, jernih, tidak gatal, dan tidak perih. Keputihan abnormal terjadi akibat infeksi dari berbagai mikroorganisme, antara lain bakteri, jamur, dan parasite (Manuaba, 2009). Keputihan yang tidak normal ditandai dengan jumlah yang keluar banyak, berwarna putih seperti susu basi, kuning atau kehijauan, gatal, perih, dan disertai bau amis atau busuk. Warna pengeluaran dari vagina akan berbeda sesuai dengan penyebab dari keputihan (Wiknjosastro, 2007). Wanita yang mengalami keputihan tidak normal merupakan indikasi dari berbagai penyakit seperti vaginitis, kandidiasis, dan trikomoniasis (Daili, 2009).

Manggis merupakan salah satu jenis buah yang dimanfaatkan sebagai pengobatan alami. Bioaktif utama dari manggis (Garcinia 
mangostana L) adalah turunan xanton. Penelitian lain juga menyebutkan bahwa ekstrak manggis (Garcinia Mangostana L) mempunyai aktivitas antioksidan, antitumor, antialergi, antiinflamasi, antibakteri, antijamur dan antiviral (Windarini, 2013).

Ekstrak etanol, dan metanol dari kulit buah manggis menunjukkan aktivitas antijamur mangostin, gartanin dan $\gamma$-mangostin terhadap Candida albicans, Cryptococcus neoformans, Trichophyton mentagrophytes dan Microsporum gypseum. (Andayani, 2016).

Sirih (Piper betle Linn.) termasuk familia Piperaceae. Tradisi makan sirih sangat populer dalam kehidupan masyarakat di Indonesia. Sirih berguna untuk kesehatan gigi dan menghilangkan bau badan dan bau mulut yang tidak sedap, sebagai obat kumur, sariawan, mimisan, gatal-gatal, koreng dan mengobati keputihan pada wanita. Daun sirih mempunyai aroma yang khas dengan kandungan minyak atsiri 4,2\% (Iptika, 2014). Komponen utama minyak atsiri adalah senyawa fenol yaitu betlephenol dan kavikol yang merupakan senyawa aromatik, dan senyawa turunannya seperti kavibetol, karvakol, eugenol, allilpyrocatechol dan ketekin. Kavikol merupakan komponen paling banyak ditemui pada daun sirih dan menyebabkan bau khas sirih. Selain itu daun sirih mengandung suatu seskuiterpen, diastase, tannin, gula dan pati. Senyawa fenol yang terkandung dalam minyak atsiri daun sirih bersifat antimikroba dan antijamur yang kuat dan efektif menghambat pertumbuhan beberapa jenis bakteri (Sumampouw, 2010).

Berdasarkan uraikan di atas bahwa ekstrak kulit buah manggis (Garcinia mangostana Linn) dan ekstrak daun sirih (Piper battle L) memiliki aktifitas sebagai antijamur khususnya terhadap Candida sp. Namun, belum diketahui bagaimana perbandingan daya antifungi dari kedua tanaman obat tradisional tersebut sehingga akhirnya nanti akan dipilih salah satunya untuk menjadi bahan baku utama pembuatan Vaginal Douches untuk mengobati keputihan secara in vitro.

\section{B. Rumusan Masalah}

Berdasarkan latar belakang yang telah diuraikan di atas dapat dirumuskan permasalahan yaitu bagaimana hasil perbandingan uji daya antifungi ekstrak cair kulit buah manggis (Garcinia mangostana L) dengan daun sirih (Piper betle 1) terhadap candida albicans secara In Vitro sebagai bahan utama pembuatan vaginal douches.

\section{Tujuan Penelitian}

Penelitian ini dilakukan untuk mengetahui perbandingan uji daya antifungi ekstrak cair kulit buah manggis (Garcinia mangostana L) dengan daun sirih (Piper betle L) terhadap candida albicans secara In Vitro sebagai bahan utama pembuatan vaginal douches.

\section{Manfaat penelitian}

Manfaat penelitian ini untuk menambah ilmu pengetahuan dalam bidang kefarmasian, dan apabila telah diperoleh hasil perbandingan dari kedua ekstrak tersebut terhadap khususnya pada candida albicans secara In Vitro maka pada penelitian selanjutnya akan dibuat suatu sediaan (produk) vaginal douches untuk mengobati keputihan.

\section{METODE PENELITIAN}

\section{A. Jenis Penelitian}

Jenis penelitian yang digunakan adalah penelitian eksperimen, dengan desain penelitian (RAL) rancangan acak lengkap.

\section{B. Waktu Dan Tempat Penelitian}

Penelitian ini dilakukan di Laboratoium Mikrobiologi dan Farmakognosi - Fitokimia Kampus Politeknik Sandi Karsa Makassar pada bulan Maret 2020.

\section{Alat dan Bahan}

Alat yang digunkan yaitu, autoklaf (Mammert), oven (Yenaco), rotavapor, mikropipet (Adjustable), Laminar Air Flow, timbangan analitik (AND), batang pengaduk, wadah maserasi, hot plate (H-HP-II), tabung reaksi, difusi cakram atau paper disk, Cawan Petri. Rak tabung, Tabung Reaksi, Spatula, Erlenmeyer, Beaker glass, Petri dish, Hotplate Magnetic stirrer, Spiritus, ose, Isolat jamur Candida albicans.

Bahan yang digunakan adalah ekstrak cair kulit buah manggis dan ekstrak cair daun sirih, etanol 96\%, jamur Candida albicans, aquadest, Larutan $\mathrm{NaCl}$ 0,9\%, Media PDA, API, dan Etanol 70\%, standar 5.0 Mc Farland, ketokonazol.

\section{Prosedur Penelitian}

Tahap penelitian ini dibagi menjadi 4 tahap yaitu :

1. Isolasi Jamur Candida albicans.

Isolasi jamur Candida albicans dilakukan untuk proses peremajaan, dan untuk mendapatkan stok tambahan isolat jamur. Pembuatan stok jamur Candida albicans dilakukan dengan menginokulasikan pada media Medium Potato Dextrosa Agar (SDA) ke dalam petri dist kemudian diinkubasi pada suhu 37o C selama 3 hari dalam incubator (Eni, 2008). 
2. Pembuatan Ekstrak Cair Kulit Buah Manggis dan Daun Sirih.

Pembuatan ekstrak cair kulit buah manggis dan daun sirih dengan konsentrasi $100 \%$ yaitu dengan menimbang masing masing kulit buah manggis dan daun sirih segar yang telah dicuci dengan air mengalir seberat $100 \mathrm{~g}$, lalu ditambahkan $100 \mathrm{ml}$ akuades kemudian di panaskan pada suhu $90^{\circ} \mathrm{C}$ selama 15 menit. Ekstrak yang dihasilkan kemudian disaring dengan menggunakan kain tipis dan saringan. Ekstrak yang sudah di dapat disaring kembali dengan menggunakan kertas saring. Ekstrak cair kulit buah manggis dan daun sirih dengan konsentrasi $100 \%$ tadi kemudian diencerkan menjadi $80 \%$ kemudian disterilkan di autoklave.

3. Pembuatan Media Pertumbuhan.

Salah satu media agar yang cocok dan mendukung pertumbuhan jamur adalah PDA (Potato Dextrose Agar) yang memilki $\mathrm{pH}$ yang rendah $(\mathrm{pH} 4,5$ sampai 5,6) sehingga menghambat pertumbuhan bakteri yang membutuhkan lingkungan yang netral dengan $\mathrm{pH} \mathrm{7,0,} \mathrm{dan} \mathrm{suhu} \mathrm{optimum} \mathrm{untuk}$ pertumbuhan antara $25-30^{\circ} \mathrm{C}$ (Cappucino, 2014).

Pembuatan Media PDA yaitu dengan cara menimbang PDA sebanyak 39 gram kemudian dimasukkan ke dalam labu Erlenmeyer, ditambahkan $1000 \mathrm{~mL}$ aquades steril. Diukur pH 5,6 \pm 2 . Media dipanaskan menggunakan hot plate sampai larut dengan sempurna. PDA kemudian disterilisasi di dalam autoklaf selama 15 menit, pada suhu $121^{\circ} \mathrm{C}$, dengan tekanan 1-2 atm. Setelah proses sterilisasi selesai, media dikeluarkan dari autoklaf, media didinginkan sampai suhu $45-50^{\circ} \mathrm{C}$. Ditambahkan kloramfenikol untuk menghambat pertumbuhan bakteri. Media PDA dituang ke dalam cawan petri setril sebanyak 15-20 mL dan dibiarkan memadat. (5378)

4. Penanaman Isolat pada Media PDA

Suspensi jamur Candida albican dioleskan secara merata pada permukaan media PDA yang sudah padat sebanyak 50 $\mu \mathrm{l}$ dengan menggunakan batang $\mathrm{L}$ steril hingga kering. Kertas cakram direndam pada masing-masing ekstrak cair kulit buah manggis dan ekstrak cair daun sirih. Kertas cakram dibuat dari kertas saring dengan cara mengguntingnya dengan alat pemotong kertas sehingga didapatkan kertas cakram yang bulat. Kemudian kertas cakram ditiriskan sesaat di bagian pinggir petridist yang steril lalu di letakkan di bagian tengah media PDA yang sudah berisi isolat
Candida albicans. Perlakuan tersebut dilakukan pada masing-masing ekstrak cair kulit buah manggis dan ekstrak cair daun sirih dengan 3 kali ulangan dan pada masing-masing pengenceran. Kontrol positif menggunakan Ketokonazol 2\% pada kertas cakram. Sedangkan kontrol negative dengan menggunakan akuades steril pada kertas cakram. Setelah itu, diinkubasi selama 3 hari pada suhu $37^{\circ} \mathrm{C}$, dan diamati pertumbuhannya serta zona bening yang terbentuk. Kemudian dilakukan pengukuran dengan menggunakan rol atau jangka sorong.

\section{E. Analisis Data}

Pengolahan data yang digunakan dalam penelitian ini adalah uji anova dilanjutkan uji BNT pada tingkat kepercayaan $95 \% \quad(\propto=0,05)$ dengan menggunakan SPSS 20.

\section{HASIL DAN PEMBAHASAN}

\section{A. Hasil Penelitian}

Tabel I. Diameter Zona Hambat

\begin{tabular}{|c|c|c|c|c|c|}
\hline \multirow[t]{3}{*}{$\begin{array}{c}\text { Kode } \\
\text { perlakuan }\end{array}$} & \multirow{2}{*}{\multicolumn{3}{|c|}{$\begin{array}{c}\begin{array}{c}\text { Diameter Zona Hambat } \\
(\mathbf{m m})\end{array} \\
\text { Replikasi }\end{array}$}} & \multirow[t]{3}{*}{$\begin{array}{l}\text { Total } \\
(\mathbf{m m})\end{array}$} & \multirow{3}{*}{$\begin{array}{r}\text { Rata } \\
\text { rata } \\
(\mathbf{m m})\end{array}$} \\
\hline & & & & & \\
\hline & 1 & 2 & 3 & & \\
\hline 1 & 0 & 0 & 0 & 0 & 0 \\
\hline 2 & 24,54 & 25,71 & 22,57 & 72,82 & 24,27 \\
\hline 3 & 13,28 & 14,57 & 12,74 & 40,59 & 13,53 \\
\hline 4 & 19,88 & 20,24 & 17,51 & 57,63 & 19,21 \\
\hline
\end{tabular}

Table I menunjukkan bahwa pada Perlakuan 1 yaitu kontrol negatif tidak menunjukkan adanya kemampuan daya hambat terhadap jamur Candida albicans, untuk perlakuan 2 yaitu kontrol positif, perlakuan 3, dan 4 memiliki daya hambat kuat dengan diameter $>8 \mathrm{~mm}$.

1. Hasil Analisis daya hambat menggunakan SPSS

Berikut hasil uji Anova dan uji BNT.

Tabel II. Hasil Uji ANOVA

\begin{tabular}{cccccc}
\hline & $\begin{array}{c}\text { Sum of } \\
\text { squares }\end{array}$ & Df & $\begin{array}{c}\text { Mean } \\
\text { Square }\end{array}$ & F & Sig. \\
\hline $\begin{array}{c}\text { Bwtween } \\
\text { Groups }\end{array}$ & 199,044 & 4 & 47,761 & 127.158 & 0.000 \\
\hline $\begin{array}{c}\text { Within } \\
\text { Groups }\end{array}$ & 3,913 & 10 & 0,391 & & \\
\hline Total & 202,957 & 14 & & & \\
\hline
\end{tabular}

Tabel II. menunjukkan bahwa ekstrak cair daun sirih memiliki nilai signifikan $0,000 \quad(<0,05)$ artinya adanya perbedaan yang signifikan dengan ekstrak cair kulit buah manggis dalam memberikan daya hambat terhadap Candida albicans. 
Tabel III. Hasil Uji BNT

\begin{tabular}{ccccccc}
\hline \multirow{2}{*}{$\begin{array}{c}\text { I) Perla } \\
\text { kuan }\end{array}$} & $\begin{array}{c}\text { (J) } \\
\text { Perla } \\
\text { kuan }\end{array}$ & $\begin{array}{c}\text { Mean } \\
\text { Difference (I-J) }\end{array}$ & $\begin{array}{c}\text { Std. } \\
\text { Error }\end{array}$ & Sig. & \multicolumn{2}{c}{$\begin{array}{c}\text { 95\% } \\
\text { Confidence } \\
\text { Internal }\end{array}$} \\
\cline { 5 - 7 } & & & & $\begin{array}{c}\text { Lower } \\
\text { Bound }\end{array}$ & $\begin{array}{c}\text { Upper } \\
\text { Bound }\end{array}$ \\
\hline 1 & 2 & 0,000 &, 51077 &, 000 & 0,000 & 0,000 \\
\hline & 3 & 0,000 &, 51077 &, 000 & 0,000 & 0,000 \\
\hline & 4 & 0,000 &, 51077 &, 000 & 0,000 & 0,000 \\
\hline 2 & 1 & $2,83333^{*}$ &, 51077 &, 000 & 1,6953 & 3,9714 \\
\hline & 3 & $-3,46667^{*}$ &, 51077 &, 000 & $-4,6047$ & $-2,3286$ \\
\hline 3 & 4 &, 20000 &, 51077 &, 704 &,- 9381 & 1,3381 \\
\hline & 1 & $6,30000^{*}$ &, 51077 &, 000 & 5,1619 & 7,4381 \\
\hline 4 & 2 & $3,46667^{*}$ &, 51077 &, 000 & 2,3286 & 4,6047 \\
\hline & 4 & $3,66667^{*}$ &, 51077 &, 000 & 2,5286 & 4,8047 \\
\hline & 2 & $2,83333^{*}$ &, 51077 &, 000 & 1,4953 & 3,7714 \\
\hline & 2 &, 20000 &, 51077 &, 704 &, 9381 & 1,3381 \\
\hline & 3 & $7,50000^{*}$ &, 51077 &, 000 & 6,3619 & 8,6381 \\
\hline
\end{tabular}

Table III menunjukkan bahwa hasil Uji BNT menunjukkan perbedaan efek yang nyata terhadap ekstrak cair kulit buah manggis (Garcinia mangostana Linn) dan daun sirih (Piper battle L) terhadap pertumbuhan jamur Candida albicans. Pada ekstrak cair daun sirih (Piper battle L) terhadap kontrol positif tidak terdapat perbedaan yang signifikan karena nilai uji BNT lebih besar dari nilai porbabilitasnya $(0,704>0,05)$.

\section{B. Pembahasan}

Pengaruh pemberian ekstrak cair kulit buah manggis (Garcinia mangostana Linn) dan ekstrak daun sirih (Piper battle L) terhadap pertumbuhan jamur Candida albicans dilihat dengan mengukur zona bening yang terbentuk untuk masing-masing ekstrak, dengan tiga kali pengulangan. Daya hambat yang dihasilkan tergantung dari ekstrak yang diberikan dan juga konsentrasinya. Dengan melakukan pengenceran pada ekstrak kulit buah manggis (Garcinia mangostana Linn) dan ekstrak daun sirih (Piper battle L) menjadi $80 \%$ terbukti bahwa semakin pekat ekstraknya maka semakin besar pula daya hambat yang dihasilkan.

Penggunaan ketokonazol 2\% membentuk zona bening yang lebih besar dari semua perlakuan. Daya hambat ini diukur dengan melihat diameter zona bening yang terbentuk yang diukur dengan menggunakan jangka sorong. Variabel yang diamati dalam penelitian ini adalah daya hambat pertumbuhan Candida albicans pada media tumbuh yang diberikan ekstrak cair kulit buah manggis (Garcinia mangostana Linn) dan ekstrak daun sirih (Piper battle $\mathrm{L})$.

Menurut Elganjar dalam Siti Ngaisah kekuatan antibakteri digolongkan menjadi 3 yaitu kuat jika menghasilkan diameter zona hambat lebih dari $8 \mathrm{~mm}$, aktivitas sedang jika menghasilkan diameter zona hambat 7-8 mm, dan aktivitas lemah jika memiliki diameter zona hambat kurang dari $7 \mathrm{~mm}$ (Siti, 2010). Oleh karena itu maka hasil pengamatan zona bening yang terbentuk menunjukkan bahwa ekstrak cair kulit buah manggis (Garcinia mangostana Linn) dan daun sirih (Piper battle L) mempunyai aktivitas antijamur yang kuat karena diameter zona hambatnya lebih dari $8 \mathrm{~mm}$.

Penggunaan ekstrak cair kulit buah manggis (Garcinia mangostana Linn) dan daun sirih (Piper battle L) dengan konsentrasi masing-masing $80 \%$ sama-sama menunjukkan zona bening. Diameter zona bening yang terbentuk dari ekstrak daun sirih (Piper battle L) lebih besar dibandingkan ekstrak cair kulit buah manggis (Garcinia mangostana Linn).

Penelitian ini juga menggunakan perlakuan kontrol positif (ketokonazol 2\%) dan kontrol negatif menggunkan akuades. Penggunaan ketokonazol 2\% bertujuan sebagai pembanding terhadap daya hambat ekstrak daun sirih pada jamur Candida albicans.

\section{PENUTUP}

\section{A. Kesimpulan}

Pengaruh pemberian ekstrak cair kulit buah manggis (Garcinia mangostana Linn) dan ekstrak daun sirih (Piper battle L) terhadap pertumbuhan jamur Candida albicans menunjukkan hasil bahwa zona bening yang terbentuk dari ekstrak cair kulit buah manggis (Garcinia mangostana Linn) dan daun sirih (Piper battle L) mempunyai aktivitas antijamur yang kuat karena diameter zona hambatnya lebih dari $8 \mathrm{~mm}$. Diameter zona bening yang terbentuk dari ekstrak daun sirih (Piper battle L) lebih besar dibandingkan ekstrak cair kulit buah manggis (Garcinia mangostana Linn).

\section{B. Saran}

Perlu dilakukan uji hambat dengan menggunakan metode ekstraksi lain untuk mendapatkan hasil yang lebih optimal.

\section{DAFTAR PUSTAKA}

Andayani R, dkk. 2016. Potensi daya hambat ekstrak kulit buah manggis (Garcinia mangostana L.) terhadap pertumbuhan Candida albicans. Journal of Syiah Kuala Dentistry Society; (1) 1: 13-20.

Azizah, N. 2015. Karakteristik Remaja Putri Dengan Kejadian Keputihan Di SMK Muhammadiyah Kudus. Jurnal JIKK, 6 (1): 57-78. 
Damayanti R, Mulyono, 2014, Khasiat dan Manfaat Daun Sirih, Agromedia Pustaka, Jakarta

Daili, Fahmi S, Indriatmi B. 2009. Penyakit Menular Seksual. Jakarta: Balai Penerbit Fakultas Kedokteran Indonesia

Fitriani, Nisa N. 2011. Hubungan Pengetahuan Tentang Perawatan Organ Genetalia Eksternal Dengan Kejadian Keputihan Pada Siswi SMK Pariwisata Satya Widya Surabaya Tahun 2011. Universitas Airlangga : Surabaya.

Iptika A. 2014. Keterkaitan Kebiasaan Dan Kepercayaan Mengunyah Sirih Pinang Dengan Kesehatan Gigi. Jurnal Unair; 3(1) : 64-69.

Lully Hanni Endarini. 2016. Modul Bahan Ajar Cetak Farmasi; Farmakognosi dan Fitokimia. Kementrian Kesehatan Republik Indonesia.

Mandal G, Divya L, Geeta Balodi. 2014. Vaginal Douching : Methotds Practices And Healt Risk, Healt Sciences Research. Vol 1, No. 4, pp 50-57

Manuaba I. A. C., Manuaba I. B. G, Manuaba I. B. 2009. Memahami Kesehatan Reproduksi Wanita. 2nd Edition. Jakarta: EGC

Mutiawati, V.K. 2016. Pemeriksaan Mikrobiologi Pada Candida albicans, Jurnal Kedokteran Syiah Kuala, Vol. 16 No. 1, 53-63.

Nurul Rahmah, dan Aditya Rahman. 2010. Uji Fungistatik Ekstrak Daun Sirih (Piper betle L.) terhadap Candida albicans. Jurnal Bioscientae, Vol. 7, No. 2, h. 17-24.

Sukma, Aldiyas. 2013. Hubungan Penggunaan Bilas Vagina Dengan Servisitis. Universitas Respati: Yogjakarta.

Sumampouw O. J. 2010. Uji In Vitro Aktivitas Antibakteri Dari Daun Sirih. Jurnal Biomedik, 2 (3) : 187 - 93.

Werdiyani, N. L. Y. 2012. Hubungan Tingkat Pengetahuan Remaja Putri Tentang Kesehatan Reproduksi Dengan Kejadian Keputihan Di SMP N 2 Bangli Bali. Yogyakarta: Universitas Respati
Wiknjosastro, H. 2007. Ilmu Kandungan. Jakarta: Yayasan Bina Pustaka Sarwono Prawirohardjo

Windarini, L. G. E. 2013. Skrining Fitokimia Ekstrak Methanol Kulit Buah Manggis (Garcinia mangostana L.). Universitas Udayana, p.1-8.

Yanuardani, D. R. 2012. Uji Daya Hambat Ekstrak Etanol dan Rebusan Daun Sirih Hijau (Piper betle) Segar Terhadap Pertumbuhan Candida albicans, Skripsi, Fakultas Keguruan dan Ilmu Pendidikan, Universitas Jember, Surabaya.

Yunitasari L. 2011. Gempur 41 Penyakit Dengan Buah Manggis, Khasiat Dan Cara Pengolahannya Untuk Pengobatan Yogyakarta: Pustaka Baru Press.

Yanuardani, D. R. 2012. Uji Daya Hambat Ekstrak Etanol dan Rebusan Daun Sirih Hijau (Piper betle) Segar terhadap Pertumbuhan Candida albicans, Skripsi, Fakultas Keguruan dan Ilmu Pendidikan, Universitas Jember, Surabaya.

Zang Jun, Thomas G, Leybovich E, 2011. Vaginal Douching And Adverse Health Effects: A Meta Analysis 